\title{
Article
}

\section{Reading sentences of words wtih rotated letters: An eye movement study}

Blythe, Hazel I., Juhasz, Barbara J., Tbaily, Lee W., Rayner, Keith and Liversedge, Simon Paul

Available at http://clok.uclan.ac.uk/24458/

Blythe, Hazel I., Juhasz, Barbara J., Tbaily, Lee W., Rayner, Keith and Liversedge, Simon Paul ORCID: 0000-0002-8579-8546 (2019) Reading sentences of words wtih rotated letters: An eye movement study. Quarterly Journal of Experimental Psychology, 72 (7). pp. 1790-1804. ISSN 1747-0218

It is advisable to refer to the publisher's version if you intend to cite from the work. http://dx.doi.org/10.1177/1747021818810381

For more information about UCLan's research in this area go to http://www.uclan.ac.uk/researchgroups/ and search for <name of research Group>.

For information about Research generally at UCLan please go to http://www.uclan.ac.uk/research/

All outputs in CLoK are protected by Intellectual Property Rights law, including Copyright law. Copyright, IPR and Moral Rights for the works on this site are retained by the individual authors and/or other copyright owners. Terms and conditions for use of this material are defined in the policies page.

\section{CLoK}

Central Lancashire online Knowledge www.clok.uclan.ac.uk

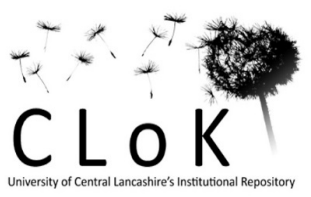


Reading sentences of words with rotated letters: An eye movement study

Hazel I. Blythe ${ }^{1}$, Barbara J. Juhasz ${ }^{2}$, Lee W. Tbaily ${ }^{1}$, Keith Rayner $^{3}$, \& Simon P. Liversedge ${ }^{4}$

\author{
${ }^{1}$ University of Southampton, UK \\ ${ }^{2}$ Wesleyan University, USA \\ ${ }^{3}$ University of California, San Diego, USA \\ ${ }^{4}$ University of Central Lancashire, UK
}

Email: hib@soton.ac.uk

Word count $=8112$

Author Note

Keith Rayner contributed to the initial design and formulation of this project, had input on the interpretation of the results, and saw an initial draft of the manuscript. Portions of these data were presented at the European Conference on Eye Movements (2015). 


\begin{abstract}
Participants' eye movements were measured as they read sentences in which individual letters within words were rotated. Both the consistency of direction and the magnitude of rotation were manipulated (letters rotated all in the same direction, or alternately clockwise and anti-clockwise; by 30 or 60 degrees). Each sentence included a target word that was manipulated for frequency of occurrence. Our objectives were threefold: To quantify how change in the visual presentation of individual letters disrupted word identification, and whether disruption was consistent with systematic change in visual presentation; to determine whether inconsistent letter transformation caused more disruption than consistent letter transformation; to determine whether such effects were comparable for words that were high and low frequency to explore the extent to which they were visually or linguistically mediated. We found that disruption to reading was greater as the magnitude of letter rotation increased, although even small rotations impacted processing. The data also showed that alternating letter rotations were significantly more disruptive than consistent rotations; this result is consistent with models of lexical identification in which encoding occurs over units of more than one adjacent letter. These rotation manipulations also showed significant interactions with word frequency on the target word: gaze durations and total fixation duration times increased disproportionately for low frequency words when they were presented at more extreme rotations. These data provide a first step towards quantifying the relative contribution of the spatial relationships between individual letters to word recognition and eye movement control in reading.
\end{abstract}


Reading rotated letter sentences

\section{Introduction}

Exploring how the visual characteristics of text influence reading and word recognition processes has a long tradition in reading research (e.g. Tinker \& Paterson, 1928) and it has been reliably demonstrated that the visual characteristics of printed words affect the ease with which they can be identified. For example, research has demonstrated that removingthespacesbetweenwords in English slows identification time, specifically increasing the duration and number of fixations readers make (e.g. Perea \& Acha, 2009; Rayner, Fischer \& Pollatsek, 1998; Sheridan, Rayner, \& Reingold, 2013; Spragins, Lefton, \& Fisher, 1976). Other studies have also shown longer identification times when the appearance of the constituent letters was manipulated, e.g. presenting them in mIxEd CaSe (Drieghe, 2008; Juhasz, Liversedge, White, \& Rayner, 2006; McConkie \& Zola, 1979; Reingold \& Rayner, 2006); alternating size (Perea \& Rosa, 2002), or with reduced contrast (e.g. Drieghe, 2008; Reingold \& Rayner, 2006). Similarly, shading a portion of a word in text results in longer processing time compared to when either the entire word is shaded or the word is presented without shading (Leyland, Kirkby, Juhasz, Pollatsek, \& Liversedge, 2013). Partial shading of the beginning half of the words causes fixations closer to the word's beginning, thus suggesting that the low-level visual cue of shading affects both eye movement control and lexical identification.

While all the investigations mentioned above involved visual manipulations that would be quite obvious to the reader, subtler visual alterations also impact word recognition and eye movement control. For example, the results of Slattery and Rayner (2013) demonstrate that subtle changes in the spaces between letters within a word (interletter spacing) can impact saccade targeting, fixation durations, and total sentence reading times. Similarly, Slattery, Yates and Angele (2016) demonstrated that the impact of interletter and interword spacing interacts 
with font type. Fonts which are proportional width produce greater inhibition from increasing interletter spacing and greater facilitation from interword spacing relative to fonts that are fixed width. When combined with additional research on interletter spacing (e.g. Cohen, Deheane, Vinckier, Jobert, \& Montavont, 2008; Paterson \& Jordon, 2010; Perea \& Gomez, 2012a, 2012b; Risko, Lanthier, \& Besner, 2011; van den Boer \& Hakvoort, 2015), and modulatory influences of constant word length on saccadic targeting (Cutter, Drieghe \& Liversedge, 2017), this suggests that readers possess a flexible eye movement system that adjusts online to low-level visual properties of the text being read.

In the present study, we investigate the flexibility of visual letter encoding and its impact on lexical identification in sentence reading through the use of individual letter rotation manipulations. Letter rotations provide an opportunity to manipulate the visual characteristics of printed words in relation to two distinct properties. First, it is possible to manipulate the magnitude of letter rotations, in order to examine the impact of distorting a word's overall visual appearance on lexical identification. As the magnitude of individual letter rotations increases, letter features such as ascenders and descenders become less visually prominent. Ordinarily, such external letter features have been shown to provide more information about the word's identity than the features on the internal line (Beech \& Mayall, 2005; Lété \& Pynte, 2003). Beech and Mayall (2005) observed that word identification was faster and more accurate when only the external letter features were used as primes compared to only the internal features. In addition, low frequency words with several ascenders or descenders (e.g., 'quilt') have been shown to be identified more quickly than those with fewer/ no ascenders or descenders in a lexical decision task (e.g., 'more'; Lété \& Pynte, 2003). These results clearly indicate that lexical identification is 
facilitated by the presence of distinct visual features at the letter level in a word (and particularly with respect to the identification of low frequency words).

Second, it is possible to manipulate the consistency of letter rotations, i.e., whether all the letters within a word are individually rotated in the same direction ("consistent"), or whether individual letters are alternately rotated clockwise and anticlockwise (“inconsistent”). This consistency manipulation can be used to investigate whether letters are encoded individually or in units of more than one letter. That is to say, if the letters of a word are encoded individually, then a letter rotation of similar magnitude applied across each constituent letter should be similarly disruptive regardless of whether the direction of rotation is uniform or alternating across letters. In contrast, if sequences of letters are encoded together, the visual word recognition system may have developed sensitivity to regularities in inter-letter consistencies (Dehaene, Cohen, Sigman and Vinckier, 2005). This may result in a greater cost to processing when letter rotations are imposed alternatively across sequences of letters, since these inter-letter consistencies would be disrupted, than when rotations are applied uniformly. In addition, for consistent rotations any reverse transformation required for letter identification can be applied uniformly over strings of consecutive letters at less processing cost than is possible across groups of non-consecutive letters, or even to each individual letter.

The examination of letter and word rotations has a long tradition in the research literature. Early studies used letters and words as stimuli to explore processes involved in the mental rotation task first introduced by Shepard and Metzler (1971) (see, e.g., Hock \& Tromley, 1978; Koriat \& Norman, 1985a,b). For example, work by Koriat and Norman (1985a) examined how rotating familiar Hebrew letters impacts processing. In this task, participants were asked to respond whether the letter was displayed normally or was a mirror-image reflection. For normal 
letters, the difference between an upright letter $\left(0^{\circ}\right)$ and one rotated $60^{\circ}$ was much smaller than for a reflected letter. However, reaction times greatly increased for normal letters rotated $120^{0}$ or more. This suggests that due to the letters' familiarity, their recognition in the $0-60^{\circ}$ range did not require the participant to use mental rotation to identify the letter and thus familiar letters' representations were found to be "broadly tuned" (p. 432).

When the task is to simply identify a letter, there does not appear to be any effect of rotation for single letters (see e.g. Koriat \& Norman, 1989), suggesting that identification of familiar letters is not affected by their orientation. This general finding has recently been extended by Risko, Medimorac, Chisholm and Kingstone (2014) who examined naming latency for 1 letter, 5 letter, and 15 letter displays as a function of both the angular rotation $\left(0^{\circ}, 45^{\circ}, 90^{\circ}\right)$ and direction of rotation. The effect of angular rotation on naming latency was significantly larger for set sizes of 5 and 15 letters compared to 1 letter. Interestingly, letters rotated in the clockwise direction (to the right) produced longer naming latencies in the 5 and 15 letter sets compared to when the letters were rotated anticlockwise (to the left) when participants were allowed to tilt their heads during the response.

Other research has examined the impact of rotating whole words, as opposed to single letters. In this research, the entire word frame is rotated as opposed to rotations of the individual letters within a word. Koriat and Norman (1985b) found only a slight increase in lexical decision times between upright Hebrew words and $60^{\circ}$ rotations, while the reaction time increase from $60^{\circ}$ to $120^{\circ}$ was dramatic. In addition, due to the fact that no effects of word length were observed in either the upright or $60^{\circ}$ condition, Koriat and Norman (1985b) reasoned that words were processed holistically at smaller magnitudes of rotation. When they examined additional orientations between $0^{\circ}$ and $60^{\circ}$, they found no effects of rotation for Hebrew words for 
orientations $40^{\circ}$ or below. Based on these results, they concluded that word recognition proceeds normally for words rotated less than $60^{\circ}$.

More recent word recognition experiments have confirmed that when words are rotated to relatively small degrees, their recognition proceeds relatively normally. Lavidor, Babkoff, and Faust (2001) presented short Hebrew words to either the right or left visual field. They observed a right visual field advantage, which is a standard finding for word recognition, for lexical decisions to words that were rotated $30^{\circ}$ or less. In a neuroimaging study, Cohen et al. (2008) presented participants with short French words presented at five different rotations clockwise or anti-clockwise $\left(0^{\circ}, 22.5^{\circ}, 45^{\circ}, 67.5^{\circ}\right.$ and $\left.90^{\circ}\right)$. Participants performed an animal detection task. The behavioral results demonstrated a significant slowing of responses beginning at $45^{\circ}$ rotations. These behavioral results, coupled with the neuroimaging data, suggest that words that are rotated past $45^{\circ}$ require effortful serial encoding of letters relative to words that are rotated to smaller degrees. The authors interpret these findings as supporting models of visual word recognition that incorporate both serial and parallel processing of letters within words (e.g. the CDP+ model, Perry, Ziegler, \& Zorzi, 2007).

The studies detailed above are informative for understanding how rotated text may impact word recognition processes. Specifically, they suggest that within a certain window of rotation (less than approximately $45^{\circ}$ ), the visual word recognition system processes letters in parallel and word recognition proceeds unimpeded. Outside of this window, the parallel processing of letters within words breaks down and a serial processing strategy appears to be employed, which greatly slows word recognition. These results with are also consistent with the Local Combination Detectors (LCDs) model proposed by Dehaene et al. (2005). According to Dehaene et al. (2005), a hierarchy of LCDs along the visual pathway contribute to word 
recognition that is invariant with respect to modest changes in case, size, and rotation. This hierarchy consists of LCDs that function as abstract letter detectors by pooling incoming activation from large numbers of case-sensitive neurons. Input from these abstract letter detectors is then passed onto bigram-sensitive LCDs. Deheane et al. (2005) further suggest that perceptual learning mechanisms allow for neurons to become dedicated to frequently occurring letter patterns. They note that while reading alphabetic languages, this perceptual learning may also allow neurons to become sensitive to the shape between letters for frequently occurring bigrams and that sensitivity to these inter-letter regularities may be one mechanism that allows readers to process handwritten text so efficiently. Based on this theory, Deheane et al. (2005) predicted that the proposed letter detectors would be disrupted by rotations greater than $40^{\circ}$ and that rotations this large or larger should disrupt normal word recognition processes.

However, there is some evidence that even letters rotated below $40^{\circ}$ may require the recruitment of additional processing resource, for example, Kim and Straková (2012) rotated individual letters in both words and pseudowords $\left(0^{\circ}, 22.5^{\circ}, 45^{\circ}, 67.5^{\circ}\right.$ and $\left.90^{\circ}\right)$. Participants completed a lexical decision task and the early stages of processing were assessed via the P1 and N170 components of recorded event-related potentials (ERPs). Both lexical decision reaction time and accuracy demonstrated nonlinear effects of rotation magnitude, with the largest difficulty arising from the $90^{\circ}$ rotation. However, both the P1 and N170 component showed enhanced responses (i.e. increased peak amplitudes) for the smallest rotation $\left(22.5^{0}\right)$ relative to the upright baseline condition. Reduced peak amplitudes were observed in both time windows for the $90^{\circ}$ rotation relative to the other rotations. Kim and Straková (2012) suggested that even the smaller rotations may require additional processing resources that are recruited as soon as approximately $100 \mathrm{~ms}$ post stimulus. 
Studies exploring single word rotation are informative for understanding how the word recognition system deals with variations in visual properties of text. However, they do not indicate the consequences to processing that would occur if the rotations were to portions of text larger than a single word. When sentences or texts are read normally, sophisticated oculomotor control in tight synchrony with linguistic processing is necessary. This means that saccades must be targeted to upcoming words, word skipping, refixation and regression decisions formulated, all in relation to ongoing lexical and higher level language comprehension processes. Thus, in a natural reading situation, it is possible that even relatively small letter rotations could much more profoundly affect eye movement control and reading when the manipulation is to portions of text larger than a single word. Only a small number of studies have examined processing of text units beyond the word that is rotated. For example, Risko et al. (2014) presented short paragraphs (40-52 words) in either an upright position or when the entire paragraph was rotated around its center $60^{\circ}$ anti-clockwise or clockwise. Overall time spent reading the paragraph aloud was greater when it was rotated than when it was presented upright, although this effect was largest when participants were told to keep their head still during the reading (i.e. they were not allowed to tilt their head). There was no effect of direction of rotation on reading aloud. Since smaller magnitudes of rotations were not tested in this study, it is still an open question as to whether an orientation of less than $60^{\circ}$ would have also impacted processing.

In the majority of above-mentioned studies examining word or text rotation, the entire word frame or paragraph was rotated around the center position as opposed to having the individual letters rotated around their center point. As in the present study, it is also useful to investigate the flexibility of visual letter encoding and its impact on lexical identification in sentence reading through the use of individual letter rotation manipulations. Initial studies using 
this manipulation were reported by Riddell, Duddy, Gibbons, and Mansfield (1997) and Gibbons and Riddell (2006), in which letter orientations varied at random, serving as a means of visually distorting text in order to compare reading performance between typical adults and those with specific reading disorder. While both groups of subjects' reading was disrupted by the letter rotations, the random nature of the manipulation meant that the disruption experienced could not be directly associated with specific characteristics of the letter rotations (e.g., rotation direction or rotation magnitude).

To our knowledge, only one other study besides Riddell et al. (1997) and Gibbons and Riddell (2006) has investigated the effect of individual letter rotations within words in a sentence reading task. Kowler and Anton (1987) individually rotated letters in sentences by $180^{\circ}$ (as well as also manipulating word and letter order), and two subjects read these sentences for comprehension whilst their eye movements were recorded. Reading speeds were slower for rotated text (457 ms - $568 \mathrm{~ms}$ per letter of text) compared to normally presented text (48ms 75ms per letter). In this study, Kowler and Anton were interested in saccade programming mechanisms rather than written language processing, and no formal analyses of the letter rotation manipulation were reported. They did report, however, that rotating individual letters $180^{\circ}$ about the horizontal axis resulted in subjects making a series of small ( $<30 \mathrm{~min}$ arc) saccades to fixate every letter, or every other letter within the word. This pattern of fixations strongly suggests that letters were encoded in a serial fashion, as would be expected based on the rotation research with single words detailed above.

In the present study, we sought to systematically examine the impact of letter rotations on the reading normal text. In order to accomplish this, participants read sentences under seven different conditions (see Figure 1). Upright sentences were presented normally in canonical 
upright form and served as a baseline. Rotated sentences (where every letter of every word was rotated to the same degree) were presented with letter rotations of either $30^{\circ}$ or $60^{\circ}$. Based on past research with letter and word rotations, disruption to reading was expected to be greater in the $60^{\circ}$ condition relative to the $30^{\circ}$ condition. When dealing with single words, rotations of $30^{\circ}$ should allow letters to be encoded in parallel and word recognition to proceed normally, consistent with the LCD theory (Dehaene et al., 2005). The current study therefore examined whether $30^{\circ}$ rotations of letters within whole sentences allow reading and eye movement control to proceed (relatively) unimpaired when compared to upright text.

In addition, the consistency and direction of rotation (clockwise and anti-clockwise) was also explored. By manipulating the consistency of the direction of rotations on a letter-by-letter basis, the spatial relationships between adjacent individual letters within words can be altered. Specifically, by rotating alternate letters clockwise and anticlockwise the degree of disruption from upright will remain the same for each individual letter but the disparity in the angle of rotation from one letter to the next will be effectively doubled (compared to when all letters are rotated in the same direction). For example, if each of the letters in a word are rotated clockwise by $30^{\circ}$ then the spatial relationships between neighbouring letters will remain intact despite the fact that they have been rotated (e.g., all ascenders and descenders will still be parallel). In contrast, if the letters of a word are rotated by $30^{\circ}$ but alternating between clockwise and anticlockwise from one letter to the next, the spatial relations between adjacent letters will be grossly disrupted (e.g., ascenders and descenders will exhibit a $60^{\circ}$ tangent). In both cases, the letters have been rotated from upright to the same extent (the distinct visual features are obscured by the same amount in relation to the overall word shape), but the spatial relationships between adjacent letters have been substantially disrupted in alternating rotations compared to consistent 
rotations. As discussed above, the LCD theory proposes that perceptual learning may allow neurons to become sensitive to inter-letter regularities during visual processing. Alternating the direction of rotation on a letter-by-letter basis will disrupt these regularities between letters and may therefore result in more processing difficulty compared to consistent rotations.

Our manipulations also allow us to examine whether the direction of consistent rotations impacts processing. One way to bring attention to a particular word or sentence within a text is to italicize it. Italicized fonts are stylized and are also rotated clockwise to a small degree. Therefore, readers may have some familiarity with text rotated clockwise from their years of experience reading italicized text. This would suggest that readers might be faster reading text when letters within words are rotated clockwise (compared to anti-clockwise). However, Risko et al. (2014) observed the opposite trend when participants named 5 or 15 letters. The clockwise rotation produced longer naming durations and no effect of direction was observed for paragraph reading. It, therefore, remains an open question as to whether an effect of the consistency of letter rotation direction will be observed, and if so, which direction of rotation (clockwise or anticlockwise) would result in more efficient processing.

Finally, the rotation manipulations of magnitude and consistency can be combined with a manipulation of word frequency to allow us to examine the impact of letter rotations on lexical processing during sentence reading. The word frequency effect is a benchmark finding in the eye movement literature (see Rayner, 2009 for a discussion). Words that occur with a high frequency in the language are processed faster than words that occur less frequently, thus, frequency provides quite a direct index of the ease with which lexical identification (a fundamental process of reading) occurs. There are two, broad alternatives for describing the relationship between word frequency and letter rotations in terms of their roles in lexical identification. First, it is 
possible that word frequency and letter rotations have additive effects, such that readers perform an initial pre-processing stage to 'clean up' the rotations before carrying out any lexical processing (e.g., Mitchell, 1982). In this case, letter rotations (applied uniformly across words) would be expected to add some constant value onto lexical identification times that does not vary with the frequency of the word. Such patterns have been reported in data from lexical decision tasks investigating the relationship between visual and linguistic manipulations on lexical identification (e.g., Becker \& Killion, 1977; Stanners, Jastrzembski, \& Westbrook, 1975) and indeed, Gomez and Perea (2014) have reported additive effects of word frequency and word rotation $\left(0^{\circ}, 45^{\circ}, 60^{\circ}\right)$ in lexical decision. A second possibility is that letter rotation effects and lexical frequency may have an interactive effect on lexical processing during reading.

For example, some letters are more visually distinct than others and may facilitate identification to a greater extent than other letters, and this may be particularly so for low frequency words (e.g., Lété \& Pynte, 2003). Several eye movement studies have demonstrated interactive effects between visual word characteristics and frequency on identification times, for example, letter size manipulations (Perea \& Rosa, 2002) or space information manipulations (Perea \& Acha, 2009). If we observed similar effects during normal reading, then we would expect to observe interactive effects of letter rotations and frequency on eye movement behaviour during reading. Specifically, we would expect a more pronounced frequency effect for low frequency words as a consequence of letter rotations, since the distinct visual features that help readers to identify those words become less prominent. 


\section{Method}

\section{Participants}

Twenty-eight native English speakers from the University of Southampton community with normal or corrected-to-normal vision and no known reading difficulties took part in the eye movement study.

\section{Apparatus}

Participants' eye movements were sampled every millisecond using a desk-mounted SR Research EyeLink 1000 eye tracker. Sentences were viewed on a white background at a distance of $70 \mathrm{~cm}$ in black Courier New font, size $14\left(0.2^{\circ}\right.$ of visual angle per character $)$. Chin and forehead rests were used in order to minimize head movements. Participants used a handheld video-game controller to indicate the end of each trial and to provide yes/no responses to comprehension questions.

\section{Materials and Design}

Sentence frames between 75-80 characters in length were constructed, each containing a 6letter target word that was either high frequency (28 -513 counts per million; mean $=96.17)$ or low frequency $(1-14$ counts per million; mean $=2.86$; frequencies taken from the CELEX database; Baayen, Piepenbrock \& Gulikers, 1995). The mean difference in frequency between target word pairs was 93 counts per million $(S D=80)$ and frequency differed significantly between the two sets of target words $(t(69)=9.73, p<0.001)$. The target word in each sentence frame was never a compound word (e.g., cowboy), was never within the first or last two words of the sentence and was always preceded by a 4-7-letter word to minimise skipping (e.g., The farmer chopped up the large potato/turnip and carrot and put them into the stew).

Individual letter rotations used in the experiment consisted of a combination of the direction of rotation (all clockwise, all anticlockwise, or alternating between clockwise and anticlockwise on a 
letter-by-letter basis) and the magnitude of rotation $\left(30^{\circ}\right.$ or $\left.60^{\circ}\right)$. A control condition in which text was not subject to any rotation was also included. Combined with the target word frequency manipulation, each sentence frame was viewed under a total of 14 conditions. For examples of the letter rotation manipulations, see Figure 1.

Insert Figure 1 about here

A Latin square design was employed in which each participant read 70 sentences frames - five were viewed under each one of the experimental conditions. The order of presentation for items across experimental conditions was randomised. Comprehension questions, requiring a yes/ no response were presented after $20 \%$ of the sentences. The mean comprehension score was $94 \%(\mathrm{SD}=6 \%$; range $=79-100 \%)$. Additionally, seven practice sentences (one for each of the rotation conditions) were created, as well as two practice comprehension questions.

\section{Procedure}

Participants were instructed to read the sentences for comprehension and to press a button on the video-game controller to indicate that they had read each sentence. Before beginning the experiment, adjustments to the chair, chin rest and forehead rest were made - and a nine-point calibration was performed, ensuring a maximum error of $0.2^{\circ}$. The practice sentences were then presented, immediately followed by the experimental sentences during which eye movement data was recorded. Calibration accuracy was checked between each trial and recalibrated if necessary. The presentation order of sentences and rotation/frequency manipulations was fully randomised. The testing session for each participant lasted approximately 30 minutes.

\section{Results}

Prior to analysis, the raw eye movement data were treated using SR Research DataViewer's 'clean' function. Firstly, any fixation that was less than $80 \mathrm{~ms}$ and was located 
within $0.5^{\circ}$ of a longer fixation was merged with that longer fixation. Next, remaining fixations lasting less than $40 \mathrm{~ms}$ that were within $1.25^{\circ}$ of a longer fixation were merged with that longer fixation. Any remaining fixations that were less than $80 \mathrm{~ms}$ or more than $2000 \mathrm{~ms}$ were removed from the data set. Data were analysed in the R Environment for Statistical Computing ( $\mathrm{R}$ Development Core Team, 2015) using the lmer function from the lme4 package (Version 1.1-7, Bates, Maechler, Bolker, \& Walker, 2014). Linear mixed models (LMMs) were used to fit the reading time measures, which were each log transformed. General linear mixed models (GLMMs) were used to fit the regression and skipping probability measures. P-values were calculated using the lmerTest function (Kuznetsova, Brockhoff, \& Christensen, 2017). Below, we report the estimated coefficient $(b)$, standard error $(S E)$ and $t$ or $z$-values from these analyses

for the main analyses. The $t$-distribution approximates the $z$-distribution, and so we interpret a $/ t /$ $>1.96$ as reflecting a statistically significant effect (Baayen, Davidson \& Bates, 2008). In the case of multiple contrasts for any one dependent measure, exact $p$-values were calculated, and a Bonferroni correction was applied. In several cases, the maximal random effects structures (e.g. Barr, Levy, Scheepers, \& Tily, 2013) would not converge, so a simpler model structure was required. A list of the specific models used for each of the analyses are provided in the Supplemental Materials.

\section{Global Analyses}

Global analyses examined eye movement measures across the entire sentences and included the measures of total sentence reading time, mean number of fixations, and regression probability ${ }^{1}$. Global sentence data are summarised in Table 1. For each dependent measure, three models were examined. In the first model each rotation condition was compared directly to the upright baseline condition in order to examine the basic cost of rotation relative to the typical 
orientation of text. This was followed by a model including direction and rotation magnitude $\left(30^{\circ}\right.$ and $\left.60^{\circ}\right)$. For direction, the clockwise and anti-clockwise rotation conditions were compared individually with the alternating condition using successive difference contrast coding. Significant interactions were further explored through the use of specific contrasts reported below. A final model was then used to directly compare clockwise and anti-clockwise rotations as a function of rotation magnitude by removing the alternating condition. The results of these LME models are shown in Table 2.

Total sentence reading time. Figure 2 depicts the effects of each manipulation on total sentence reading times. As can be observed, sentence reading times were significantly longer for each of the rotation conditions relative to the upright condition (Model 1). In Model 2, where the direction and magnitude of rotations were compared, the alternating condition produced the longest sentence reading times while the clockwise condition produced the shortest reading times. Larger magnitudes of rotations also produced a greater increase in sentence reading times. Both direction comparisons (Alternating vs. Anti-clockwise and Clockwise vs. Alternating) interacted with the magnitude of rotation, showing a greater cost of the $60^{\circ}$ rotations for alternating text relative to both the consistent rotation conditions. Finally, Model 3 showed that clockwise rotations caused significantly longer reading times than anticlockwise rotations. There was again a main effect of rotation magnitude and an interaction between direction of rotation and magnitude. In order to explore this interaction further, contrasts were used to compare the $30^{\circ}$ and $60^{\circ}$ magnitudes for each direction separately. These contrasts demonstrated a significant effect of rotation magnitude for each direction (Anti-clockwise $t=13.61$, Clockwise, $t=16.17$ ). The significant interactions between direction and magnitude in Models 2 and 3 stem from the fact that the impact of rotation magnitude was largest in the alternating condition (6469 ms), 
followed by the clockwise rotation condition $(2533 \mathrm{~ms})$, then the anti-clockwise rotation condition (1957 ms).

Number of fixations per sentence. The analyses for mean number of fixations mostly mirrored the total sentence reading time analyses. In Model 1, each rotation condition resulted in significantly more fixations on the sentences relative to the upright condition. Model 2 demonstrated that the alternating condition resulted in more fixations on the sentences compared to both the anti-clockwise rotation and the clockwise rotation. Rotations of $60^{\circ}$ produced more fixations than rotations of $30^{\circ}$. In addition, both direction comparisons interacted with rotation magnitude. Contrasts to examine the interaction between rotation direction and magnitude again showed significantly more fixations for $60^{\circ}$ rotations compared to the $30^{\circ}$ rotations for each direction (Anti-clockwise $t=11.53$, Clockwise $t=13.11$, Alternating $t=26.68$ ), showing that the effect of rotation magnitude was much more pronounced for the alternating condition (18.7 fixations) compared to anti-clockwise (6.2 fixations) or clockwise (6.9 fixations) rotations. In the third model the interaction between direction and rotation magnitude was not significant, but the comparison of anti-clockwise versus clockwise rotations was marginal $(t=1.90, p=0.06)$ and magnitude of rotation was again significant in this model.

Regression probability. Model 1 showed that the probability of making a regression in a sentence was significantly higher for both $30^{\circ}$ and $60^{\circ}$ alternating conditions, as well as the $60^{\circ}$ clockwise and anticlockwise conditions, relative to the baseline upright condition. Neither the anti-clockwise nor the clockwise $30^{\circ}$ conditions differed significantly from upright text. Each of the main effects and interactions were significant in Model 2. Contrasts examining the interaction between direction and magnitude again showed significant effects of magnitude of rotation for each direction (Anti-clockwise, 3\%, $z=2.29, p<.002$; Clockwise, $3 \%, z=3.24, p=$ 
.001 ; Alternating, $7 \%, z=11.63, p<.001)$. Finally, Model 3 only produced a significant effect of rotation magnitude. Neither the comparison of anti-clockwise and clockwise rotations, nor the interaction with rotation magnitude were significant.

Summary of global analyses. The patterns of results from the global analyses are quite clear. First, each rotation condition produced disruption to reading compared to the upright baseline with the exception of the $30^{\circ}$ anti-clockwise and clockwise rotations in regression probability. However, these conditions did demonstrate disruption for total sentence reading and total number of fixations, suggesting that even relatively small consistent rotations require readers to make additional fixations to support sentence processing. Second, across all dependent measures, the $60^{\circ}$ rotations were more disruptive to reading and eye movement control than $30^{\circ}$ rotations. The size of this effect was greatest for alternating text in all measures, although it was significant for the anti-clockwise and clockwise rotations as well. Third, the consistency and direction of rotation also impacted processing. Alternating text produced more disruption to reading and eye movements than consistently rotated text. When the anti-clockwise rotations were directly compared to clockwise rotations, an advantage for text rotated anti-clockwise was observed in the total sentence reading time measure and the number of fixations (though the latter effect was only marginal).

\section{Local Analyses}

In order to examine the effect of letter rotations on lexical identification more directly, we conducted further analyses on the target word per sentence that was manipulated for frequency. Local analyses focused on the critical target word. Three dependent measures were examined; first fixation duration (the duration of the initial fixation on the word), gaze duration (the sum of all fixations on the word until fixating another word) and total fixation time (the sum 
of all fixations made on the word). Means for the target word are presented in Table 3. As with the global analysis, three models were examined for each dependent measure. In the first model each rotation condition was compared directly to the upright baseline condition in order to examine the basic cost of rotation relative to the typical orientation of words. This was followed by a model including direction, rotation magnitude $\left(30^{\circ}\right.$ and $\left.60^{\circ}\right)$, and target word frequency (high and low) along with the interaction terms. As before, the anti-clockwise and clockwise rotation conditions were each compared with the alternating condition using successive difference coding. The third model directly compared anti-clockwise and clockwise rotations without the alternating condition included. This model also included rotation magnitude, word frequency, and the interaction terms. Contrasts were used to examine significant interactions in Models 2 and 3. The results of these LME models are shown in Table 4.

Model 1. When examining reading times on the target word, each of the rotation conditions produced significantly slower first fixation durations, gaze durations, and total fixation durations relative to upright text.

\section{Model 2.}

Main effects. The comparison of the anti-clockwise rotation condition relative to the alternating condition was significant in all measures, showing that alternating text produced significant disruption to target processing relative to consistent anti-clockwise rotations. Alternating text also produced significantly longer reading times relative to the consistently rotated conditions. Across all measures, text rotated $60^{\circ}$ produced significantly slower target word processing relative to text rotated $30^{\circ}$. A main effect of word frequency was also observed in each dependent measure. 
Interactions. The interaction terms did not reach significance in the model for first fixation duration. In gaze duration and total fixation duration, which incorporate refixations and fixations made after a regression to the target word respectively, significant interactions were observed between direction (anticlockwise vs. alternating and alternating vs. clockwise) and the magnitude of rotation. Contrasts were used to examine the effect of rotation magnitude $\left(30^{\circ}\right.$ vs. $60^{\circ}$ ) for each direction separately (three contrasts for each dependent measure; Bonferronicorrected significance level $=0.017$ ). The magnitude effect was largest for alternating text (gaze duration $636 \mathrm{~ms}, t=19.18, p<0.001$; total fixation duration $1118 \mathrm{~ms}, t=20.23, p<0.001$ ), following by clockwise rotations (gaze duration $293 \mathrm{~ms}, t=13.52, p<0.001$; total fixation duration $458 \mathrm{~ms}, t=12.70, p<0.001$ ), then anti-clockwise rotations (gaze duration $167 \mathrm{~ms}, t=$ 8.76, $p<0.001$; total fixation duration $319 \mathrm{~ms}, t=9.31, p<0.001)$, although the effect was significant for each direction.

A significant interaction was also observed between direction (anticlockwise vs. alternating) and word frequency in gaze duration (marginal in total fixation time). Here, two contrasts were run for each dependent measure, to examine the frequency effect for each rotation direction (Bonferroni-corrected significance level $=0.025)$. There was a larger effect of word frequency in the alternating condition (gaze duration $221 \mathrm{~ms}, t=4.93, p<0.001$; total fixation duration 463ms, $t=5.98, p<0.001$ ) relative to the anticlockwise condition (gaze duration $57 \mathrm{ms,}$ $t=2.28, p=0.023$; total fixation duration $185 \mathrm{~ms}, t=4.09, p<0.001)$. Finally, in the total fixation duration measure there was a significant interaction between magnitude of rotation and word frequency, because the magnitude of the frequency effect was larger for the $60^{\circ}$ rotations than for the $30^{\circ}$ rotations (both $t \mathrm{~s}>4$, both $p \mathrm{~s}<0.001$ ). 
Model 3. Note that this model is the same as Model 2, but without the alternating condition. This allowed us to directly compare the clockwise and anticlockwise conditions, and related interactions. We focus on these effects here, and do not discuss effects that are repetitions of those from Model 2. (e.g., word frequency and angle of rotation).

Main Effects. Target words rotated anticlockwise received significantly shorter first fixation durations, gaze durations, and total fixation durations, relative to target words rotated clockwise.

Interactions. Once again, there were no significant interactions present in first fixation duration. In both the gaze duration and total fixation duration measures, significant interactions emerged between direction and rotation magnitude. The contrasts reported for Model 2 illustrate a larger effect of rotation magnitude for clockwise rotations compared to anticlockwise rotations, although both were significant.

Summary of local analyses. When examining target word processing within a sentence, each rotation magnitude and direction produced significantly longer reading times relative to the upright condition, thus suggesting that even small and consistent rotations disrupted normal word recognition processes. Consistent with the overall sentence analyses, alternating rotations produced larger disruptions than rotations anti-clockwise or clockwise. Likewise, target words rotated anti-clockwise were read significantly faster compared to those rotated clockwise in all measures. For all duration measures, a greater magnitude of rotation produced larger disruptions to target word recognition. The benchmark word frequency effect was also evident in each measure, with high frequency words being fixated for less time than low frequency words. Some interactions were observed in gaze durations, which takes refixations into account, and total fixation duration, which includes regressions back to the target word. These illustrated a larger 
effect of rotation magnitude for alternating rotations, followed by clockwise, and then anticlockwise rotations. Interactions also demonstrated that the effect of word frequency was also more pronounced for alternating text relative to anti-clockwise rotations in gaze duration and total fixation duration and for larger magnitude of rotations in total fixation durations.

\section{Discussion}

The present study investigated how visual disruptions to text through the use of individual letter rotations impact eye movement control and lexical identification in a normal reading task. Reading times were measured for sentences in which the individual letters were rotated, and were compared against a baseline condition in which text was presented normally. The magnitude of the letter rotations was either $30^{\circ}$ or $60^{\circ}$, and the direction of the individual letter rotations was varied such that letters were either rotated consistently, or alternated between clockwise and anticlockwise on a letter-by-letter basis. Additionally, a single target word within each sentence was manipulated for frequency. This project is the first step in a line of research that seeks to quantify the relative contributions of individual letters and their spatial positions within words to lexical identification. As such, it provides information on how the disruption of spatial relationships between letters within a word (as realized in the alternating conditions) impacts reading behaviour. Below we detail several of the key findings from these data and highlight how they bear on theories of letter encoding and word recognition during reading.

\section{Magnitude of Rotation}

Based on past research with single words (e.g. Cohen et al., 2008; Koriat \& Norman, $1985 \mathrm{~b}$ ), it was expected that $60^{\circ}$ rotations of the letters within a sentence would produce greater disruption relative to $30^{\circ}$ rotations to overall sentence reading, eye movement control, and target word identification. This expectation was confirmed for all measures examined in the present 
study. Thus, a greater magnitude of rotation produces a larger negative impact on language processing and eye movement control during reading. This effect is also predicted by previous research on the role of word shape information in word identification (e.g. Beech \& Mayall, 2005; Lété \& Pynte, 2003; Perea \& Rosa, 2002), since larger rotations result in a greater deviation from the shape of a word in its upright form.

One open question based on past research was what impact (if any), consistent text rotations at a relatively small magnitude $\left(30^{\circ}\right)$ would have when compared to upright text. To briefly review, past studies using single words have illustrated that word recognition proceeds normally when words are rotated less than approximately $45^{\circ}$ around their center. This has been attributed to readers' ability to continue to process letters in parallel within words at these small rotation magnitudes. As the degree of rotation increases, neuroimaging and behavioral results suggest that a reader must engage in more effortful serial letter processing, which will slow word identification (Cohen et al., 2008). The current study extended this work by rotating letters within a word (as opposed to the word frame itself), following the work of Kim and Straková (2012) and by applying the rotation manipulation to the entire sentence, as opposed to an isolated word. Global analyses on the entire sentence demonstrated a cost for small rotations on the mean number of fixations and the total sentence reading time. Readers require additional fixations, and therefore additional processing time, when presented with even small magnitudes of letter rotations. Note that it is not simply the case that they make the same number of fixations of a longer duration - readers require additional fixations to read effectively. There was also a cost for text consistently rotated $30^{\circ}$ relative to the upright condition for all measures of target word processing. However, the magnitude of this effect on the target word was relatively modest, on the order of $35 \mathrm{~ms}$ for the consistent rotations in gaze duration. Taken together, these results 
suggest that the $30^{\circ}$ consistent rotations in the present study do impact reading and word recognition processes, but the effects are much more subtle than for larger rotations. These results provide converging evidence with Kim and Straková (2012) that even relatively small rotations may require additional processing resources to support effective word recognition. Taken together, this suggests that predictions of the LCD model (Deheane et al., 2005) which suggest that letter detectors, and hence word recognition, will not be disrupted by rotations less than $40^{\circ}$, should be revised.

\section{Direction of Rotation}

There were robust effects of rotation consistency across all global sentence measures as well as target word reading - alternating clockwise/ anticlockwise rotations were far more disruptive to reading than consistent rotations. This result suggests that the spatial relationships between adjacent letters are important for lexical identification. In many of the measures of processing (total sentence reading time, number of fixations, regression probability, gaze duration on the target word, total fixation duration on the target word), the effect of rotation magnitude was also found to be largest for alternating rotations indicating that $60^{\circ}$ alternating rotations are particularly detrimental to reading. To reiterate, both consistent and alternating rotations manipulated letters by the same magnitude from their upright orientation, the only difference between these conditions was that spatial relationships between adjacent letters were disrupted (e.g., ascenders are no longer parallel).

As is evident from examining the $60^{\circ}$ alternating condition in Figure 1, the shape between the letters was severely disrupted in this condition, especially when ascenders and descenders were present. Our finding of significant disruption in this condition provides support for the idea that perceptual learning of inter-letter consistencies can support effective word 
recognition as discussed in the LCD theory (Deheane et al., 2005). When these inter-letter consistencies are removed, word recognition and reading performance significantly suffers. While we feel that the LCD theory provides a plausible mechanistic account of these findings, other explanations could also be plausible. Future research could examine whether similar effects are observed in words devoid of ascenders and descenders, to explore the role of these distinct visual features. In addition, since readers are most familiar with connected text presented with lowercase letters, it may also be informative to explore the impact of alternating rotations in text presented in using only uppercase letters, similar to work that has been done with isolated word recognition (e.g., Perea, Marcet, \& Fernández-López, 2018). WITH SENTENCES IN UPPERCASE, perceptual learning for inter-letter shape would be expected to be weaker and therefore alternating rotations may not be as detrimental to reading as was observed in the present study.

The direct comparison of the anti-clockwise and clockwise consistent conditions yielded a significant effect for total sentence reading time as well as first fixation duration, gaze duration, and total fixation duration on the target word itself. In each of these measures, text rotated anticlockwise was processed faster than text rotated clockwise. This is consistent with Risko et al.'s (2014) finding with 5 and 15 letter displays. It is inconsistent with the idea that familiarity with italicized text would produce an advantage for text rotated consistently to the right. While speculative, it is possible that experience with italicized text did play a role in producing these results. Since text is often italicized to draw readers' attention to it, it is possible that readers have developed a strategy of reading italicized text more slowly in order to process the meaning more deeply. Slower reading of italicized text may, therefore, not reflect disruption to processing, but instead focused processing to attain deeper understanding. Of course, italicized 
text is rotated to the right to a smaller degree than that used in the present study. The possibility that familiarity with italicized text impacts how readers deal with rotated text, therefore, requires further investigation in the future. We note, though, that consistent with our suggestion, there is some evidence from both laboratory and classroom settings that more is remembered from "disfluent" text that is presented in hard-to-read fonts including those that are italicized (Diemand-Yauman, Oppenheimer, \& Vaughan, 2011). However, this advantage for disfluent text has not been observed consistently in all domains (see the discussion by Bjork \& Yue, 2016). For example, Strukelj, Scheiter, Nyström, and Holmqvist (2016) investigated the role of disfluency on recall for text in an eye movement study and observed very limited effects of dysfluency on reading behaviour.

\section{The Effects of Rotations on Word Recognition}

A word frequency effect was evident in each fixation duration measure on the target word, thus demonstrating that the word frequency manipulation in the present study was effective. As outlined in the Introduction, we wished to examine whether rotations and frequency have additive effects, where readers initially 'clean up' the rotations before carrying out any lexical processing, or whether the rotation manipulations would interact with word frequency. In this case, the rotation conditions would be expected to produce a larger frequency effect as visual features that aid word recognition for low frequency words may become less prominent due to rotations. In fact, our results showed that main effects for the earliest measures of processing on the target word. This is consistent with the additive effects of word frequency and rotation magnitude in lexical decision reported by Gomez and Perea (2014). However, in the current study interactive effects were observed for the later measures of processing indexed by gaze duration and total fixation duration. 
In other words, there is evidence for both types of influence on processing, and the present results demonstrate that the nature of the influence of letter rotations and word frequency on processing varied in relation to the time-course of processing. The magnitude of the word frequency effect for each condition in the present study as a function of the four target word duration measures is illustrated in Figure 3. As can be observed, there were no significant interactions between any of the rotation manipulations and word frequency in the earliest measure of target word processing, first fixation duration. In the upright condition, the effect of word frequency was $24 \mathrm{~ms}$ in first fixation duration. The magnitude of word frequency effects was relatively consistent across all manipulations on these duration measures (ranging from $11 \mathrm{~ms}-33 \mathrm{~ms})$. However, as illustrated by the interactions in gaze duration and total fixation duration, the effect of word frequency was much more pronounced for alternating rotations relative to consistent rotations. Gaze duration, which takes refixations on the target word into account, is often linked to the completion of word recognition. This interaction suggests that alternating text was more detrimental to the recognition of low frequency words. As noted previously, recognition of low frequency words in particular is facilitated when there are distinct visual features. Alternating text affects the nature of the relationship of these visual features, and this is more disruptive for low frequency words. An interaction between rotation magnitude and word frequency was also observed in total fixation duration, which includes fixations after regressions back to the target word. One possibility is that the difficult rotation conditions may have also taxed working memory and therefore negatively impacted text integration processes in addition to word recognition.

\section{Conclusions}


The present study adds to the tradition of exploring how visual factors affect eye movement control and word recognition during reading. It extends work that has examined letter and word rotations to a more natural sentence reading task. The use of eye movement recording allows examinations of global sentence processing, eye movement control, and the lexical identification of target words. As mentioned above, this project represents a first step towards examining the contributions of individual letters and their positions within words to lexical identification. The results suggest that both eye movement control and sentence processing are affected by text rotations, with larger magnitudes of rotation and rotations that interrupt the spatial relationships of letters producing the greatest disruption. These disruptions are greatest for low frequency words, since their recognition may rely more on unique visual features of letters. However, even relatively small rotations produce decrements in word recognition, a finding that is surprising given past research with single words. Since all letters were rotated in each sentence, future research may wish to explore whether small rotations would produce slower processing if only the letters within a single target word were rotated. These rotations could also be used as a way to further explore the impact of text disfluency on recall and comprehension from print. Future projects may further explore the impact of rotations for specific letters and letter sequences on lexical identification and eye movement control in order to quantify the contribution of a given letter to word recognition processes. 


\section{References}

Baayen, R. H., Piepenbrock, R., \& Gulikers, L. (1995). The CELEX Lexical Database (CDROM). Philadelphia: Linguistic Data Consortium, University of Pennsylvania.

Barr, D.J., Levy, R., Scheepers, C., \& Tily, H.J. (2013). Random effects structure for confirmatory hypothesis testing: Keep it maximal. Journal of Memory and Language, 68, $255-278$.

Bates, D., Maechler, M., Bolker, B., \& Walker, S. (2014). lme4: Linear mixed-effects models using Eigen and S4 classes (R Package Version 1.1-7). Retrieved from http://CRAN.Rproject.org/package $=\operatorname{lme} 4$

Becker, C. A., \& Killion, T. H. (1977). Interaction of visual and cognitive effects in word recognition. Journal of Experimental Psychology: Human Perception and Performance, $3(3), 389-401$.

Beech, J. R., \& Mayall, K. A. (2007). The word shape hypothesis re-examined: evidence for an external feature advantage in visual word recognition. Journal of Research in Reading, 28(3), 302-319.

Bjork, R.A., \& Yue, C.L. (2016). Commentary: Is disfluency desirable? Metacognition and Learning, 11, 133-137.

Cohen, L., Deheane, S., Vinckier, F., Jobert, A., \& Montavont, A. (2008). Reading normal and degraded words: Contributions of the dorsal and ventral visual pathways. NeuroImage, 40, 353-366.

Cutter, M. G., Drieghe, D., \& Liversedge, S. (2017). Reading sentences of uniform word length: evidence for the adaptation of the preferred saccade length during reading. Journal of Experimental Psychology Human Perception \& Performance, 43, 1895 - 1911. 
Davis, C. J. (1999). The self-organising lexical acquisition and recognition (SOLAR) model of visual word recognition (Doctoral dissertation, University of New South Wales, Sydney, New South Wales, Australia, 1999). Dissertation Abstracts International, 62, 594.

Dehaene, S., Cohen. L., Sigman, M., \& Vinckier, F. (2005). The neural code for written words: A proposal. TRENDS in Cognitive Science, 9, 335-341.

Diemand-Yauman, C., Oppenheimer, D.M., \& Vaughan, E.B. (2011). Fortune favors the bold (and the italicized): Effects of disfluency on educational outcomes. Cognition, 118, 111115.

Drieghe, D. (2008). Foveal processing and word skipping during reading. Psychonomic Bulletin \& Review, $15,856-860$.

Juhasz, B.J., Liversedge, S.P., White, S.J., \& Rayner, K. (2006). Binocular coordination of the eyes during reading: Word frequency and case alternation affect fixation duration but not fixation disparity. The Quarterly Journal of Experimental Psychology, 59, 1614-1625

Gibbons, W., \& Riddell, P. (2006). Visual noise in adults with specific reading disorder. Perception, 35 (ECVP Abstract Supplement).

Gomez, P., \& Perea, M. (2014). Decomposing encoding and decisional components in visualword recognition: A diffusion model analysis. Quarterly Journal of Experimental Psychology, 67, 2455-2466.

Hock, H.S., \& Tromley, C.L. (1978). Mental rotation and perceptual uprightness. Perception \& Psychophysics, 24, 529-533.

Kim, A.E., \& Straková, J. (2012). Concurrent effects of lexical status and letter-rotation during early stage visual word recognition: Evidence from ERPs. Brain Research, 1468, 52-62. 
Koriat, A., \& Norman, J. (1985a) Mental rotation and visual familiarity. Perception \& Psychophysics, 37, 429-439.

Koriat, A., \& Norman, J. (1985b). Reading rotated words. Journal of Experimental Psychology: human Perception and Performance. 11 (4), 490-508.

Koriat, A., \& Norman, J. (1989). Why is word recognition impaired by disorientation while the identification of single letters is not? Journal of Experimental Psychology: Human Perception and Performance, 15, 153-163.

Kowler, E. \& Anton, S. (1987). Reading twisted text: Implications for the role of saccades. Vision Research. 27, 45-60.

Kuznetsova A, Brockhoff PB and Christensen RHB (2017). lmerTest Package: Tests in Linear Mixed Effects Models. Journal of Statistical Software, 82, 1-26.

Lavidor, M., Babkoff, H., \& Faust, M. (2001). Analysis of standard and non-standard visual word format in the two hemispheres. Neuropsychologia, 39, 430-439.

Lété, B., \& Pynte, J. (2003). Word-shape and word-lexical frequency effects in lexical-decision and naming tasks. Visual Cognition, 10(8), 913-948.

Leyland, L.-A, Kirkby, J.A., Juhasz, B.J., Pollatsek, A., \& Liversedge, S.P. (2013). The influence of word shading and word length on eye movements during reading. The Quarterly Journal of Experimental Psychology, 66, 471-486.

McConkie, G. W., \& Zola, D. (1979). Is visual information integrated across successive fixations in reading? Perception and Psychophysics, 25, 221-224.

McClelland, J. L., \& Rumelhart, D. E. (1981). An interactive activation model of context effects in letter perception: Part 1. An account of basic findings. Psychological Review, 88, 375407. 
Mitchell, D. C. (1982). The process of reading: a cognitive analysis. Chichester: John Wiley.

Paterson, K.B., \& Jordon, T.R. (2010). Effects of increased letter spacing on word identification and eye guidance during reading. Memory \& Cognition, 38, 502-512.

Perea, M. \& Acha, J. (2009). Space information is important for reading. Vision Research, 49, 1994-2000.

Perea, M., \& Gomez, P. (2012a). Increasing interletter spacing facilitates encoding of words. Psychonomic Bulletin \& Review, 19, 332-338.

Perea, M., \& Gomez, P. (2012b). Subtle increases in interletter spacing facilitate the encoding of words during normal reading. PLoS ONE, 7(10), e47568.

Perea, M., Marcet, A., \& Fernández-López, M. (in press). Does letter rotation slow down orthographic processing in word recognition? Psychonomic Bulletin \& Review.

Perea, M., \& Rosa, E. (2002). Does “whole word shape" play a role in visual word recognition? Perception and Psychophysics, 64, 785-794.

Perry, C., Ziegler, J.C., \& Zorzi, M. (2007). Nested incremental modelling in the development of computational theories: The CDP+ model of reading aloud. Psychological Review, 114, 273-315.

Rayner, K. (2009). Eye movements and attention in reading, scene perception, and visual search. The Quarterly Journal of Experimental Psychology, 62, 1457-1506.

Rayner, K., Fischer, M.H., \& Pollatsek, A. (1998). Unspaced text interferes with both word identification and eye movement control. Vision Research, 38, 1129-1144.

Reingold, E., \& Rayner, K. (2006). Examining the word identification stages hypothesized by the E-Z Reader model. Psychological Science, 17, 742-746. 
Riddell, P., Duddy, J., Gibbons, W., \& Mansfield, S. (1997). Do textual distortions affect normal and reading disabled adults equally? Investigative Ophthalmology and Visual Science, Supplement, 38, S647.

Risko, E.F., Lanthier, S.N., \& Besner, D. (2011). Basic processes in reading: The effect of interletter spacing. Journal of Experimental Psychology: Learning, Memory, and Cognition, 37, 1449-1457.

Risko, E.F., Medimorec, S., Chisholm, J., \& Kingstone, A. (2014). Rotating with rotated text: A natural 34ehaviour approach to investigating cognitive offloading. Cognitive Science, 38, $537-564$.

Rumelhart, D. E., \& McClelland, J. L. (1986). On learning the past tenses of English verbs. In D. E. Rumelhart \& J. L. McClelland (Eds.), Parallel distributed processing, Vol 2: Explorations in the microstructure of cognition (pp. 216-271). Cambridge, MA: MIT Press.

Shepard, R.N., \& Metzler, J. (1971). Mental rotation of three dimensional objects. Science, 171, 701-703.

Sheridan, H., Rayner, K., \& Reingold, E.M. (2013). Unsegmented text delays word identification: Evidence from a survival analysis of fixation durations. Visual Cognition, $21,38-60$.

Slattery, T.J., \& Rayner, K. (2013). Effects of intraword and interword spacing on eye movements during reading; Exploring the optimal use of space in a line of text. Attention, Perception, \& Psychophysics, 75, 1275-1292. 
Reading rotated letter sentences

Slattery, T.J., Yates, M., \& Angele, B. (2016). Interword and interletter spacing effects during reading revisited: Interactions with word and font characteristics. Journal of Experimental Psychology: Applied, 22, 406-422.

Spragins, A. B., Lefton, L. A. \& Fisher, D. F. (1976). Eye movements while reading and searching spatially transformed text: A developmental examination. Memory \& Cognition, 4, 3642.

Stanners, R. F., Jastrzembski, J. E., and Westbrook, A. (1975). Journal of Verbal Learning and Verbal Behaviour, 14, 259-264.

Strukelj, A., Scheiter, K., Nyström, M., \& Holmqvist, K. (2016). Exploring the lack of a disfluency effect: Evidence from eye movements. Metacognition and Learning, 11, 7188.

Tinker, M.A., \& Paterson, D.G. (1928). Influence of type form on speed of reading. The Journal of Applied Psychology, 12, 359-368.

Van den Boer, M., \& Hakvoort, B.E. (2015). Default spacing is the optimal spacing for word reading. The Quarterly Journal of Experimental Psychology, 68, 697-709.

Whitney, C., \& Berndt, R. S. (1999). A new model of letter string encoding: Simulating right neglect dyslexia. In J. A. Reggia, E. Ruppin, \& D. Glanzman (Eds.), Progress in brain research (Vol. 121, pp. 143-163), Amsterdam: Elsevier. 
Reading rotated letter sentences

${ }^{1}$ We also examined word skipping probability and mean fixation duration as global measures. These additional measures patterned very similarly to those reported in full and so, for the sake of brevity, are not included here. 
Table 1

Global Sentence Measures

\begin{tabular}{lcccccc}
\hline & & $\begin{array}{c}\text { Total } \\
\text { sentence } \\
\text { reading time }\end{array}$ & $\begin{array}{c}\text { Number of } \\
\text { fixations }\end{array}$ & $\begin{array}{c}\text { Fixation } \\
\text { duration }\end{array}$ & $\begin{array}{c}\text { Regression } \\
\text { probability }\end{array}$ & $\begin{array}{c}\text { Skipping } \\
\text { probability }\end{array}$ \\
\hline Upright & & $3483(1793)$ & $15.1(6.7)$ & $217(120)$ & $0.20(0.03)$ & $0.39(0.10)$ \\
Anticlockwise & $30^{\circ}$ & $3963(1594)$ & $17.0(5.9)$ & $220(116)$ & $0.21(0.02)$ & $0.33(0.09)$ \\
& $60^{\circ}$ & $5920(2696)$ & $23.2(11.3)$ & $248(124)$ & $0.24(0.03)$ & $0.26(0.09)$ \\
Alternating & $30^{\circ}$ & $4524(1805)$ & $18.9(6.8)$ & $223(109)$ & $0.22(0.03)$ & $0.30(0.10)$ \\
& $60^{\circ}$ & $10993(4740)$ & $37.6(16.1)$ & $296(164)$ & $0.29(0.02)$ & $0.24(0.14)$ \\
Clockwise & $30^{\circ}$ & $3972(1520)$ & $17.1(6.0)$ & $217(114)$ & $0.21(0.02)$ & $0.33(0.08)$ \\
& $60^{\circ}$ & $6505(3010)$ & $24.0(9.6)$ & $255(130)$ & $0.24(0.03)$ & $0.23(0.08)$
\end{tabular}

Note. Mean (standard deviation) values for measures across the entire sentences. All reading time measures are reported in ms. 
Table 2. LME results for global measures.

\begin{tabular}{|c|c|c|c|c|c|c|c|c|c|c|}
\hline & & \multicolumn{3}{|c|}{ Total sentence time } & \multicolumn{3}{|c|}{ Number of fixations } & \multicolumn{3}{|c|}{ Regression probability } \\
\hline & & $\mathrm{B}$ & $\mathrm{SE}$ & $\mathrm{t}$ & $\mathrm{B}$ & SE & $\mathrm{t}$ & $\mathrm{B}$ & $\mathrm{SE}$ & $\mathrm{Z}$ \\
\hline \multirow[t]{7}{*}{ Model 1} & Baseline (upright) & 8.07 & 0.05 & 158.14 & 2.65 & 0.06 & 47.94 & -1.52 & 0.11 & 13.93 \\
\hline & Alternating, $30^{\circ}$ & 0.28 & 0.02 & $13.14^{* * *}$ & 0.24 & 0.02 & $10.27^{* * *}$ & 0.13 & 0.05 & $2.33^{*}$ \\
\hline & Anticlockwise, $30^{\circ}$ & 0.15 & 0.02 & $7.03^{* * *}$ & 0.14 & 0.02 & $5.90^{* * * *}$ & 0.08 & 0.06 & 1.47 \\
\hline & Clockwise, $30^{\circ}$ & 0.16 & 0.02 & $7.28^{* * *}$ & 0.15 & 0.02 & $6.50^{* * *}$ & 0.04 & 0.06 & 0.79 \\
\hline & Alternating, $60^{\circ}$ & 1.17 & 0.02 & $53.42^{* * * *}$ & 0.90 & 0.05 & $20.00^{* * *}$ & 0.52 & 0.05 & $10.89^{* * * *}$ \\
\hline & Anticlockwise, $60^{\circ}$ & 0.55 & 0.02 & $25.56^{* * * *}$ & 0.43 & 0.03 & $14.73^{* * *}$ & 0.21 & 0.05 & $4.00^{* * *}$ \\
\hline & Clockwise, $60^{\circ}$ & 0.63 & 0.02 & $29.34^{* * *}$ & 0.47 & 0.04 & $12.76^{* * *}$ & 0.22 & 0.05 & $4.31^{* * *}$ \\
\hline \multirow[t]{6}{*}{ Model 2} & Intercept & 8.56 & 0.05 & 179.90 & 3.03 & 0.04 & 68.13 & -1.34 & 0.11 & 12.26 \\
\hline & Direction (Ant.-Alt.) & 0.37 & 0.02 & $19.36^{* * *}$ & 0.29 & 0.02 & $16.66^{* * *}$ & 0.17 & 0.03 & $5.17^{* * *}$ \\
\hline & Direction (Cl.-Alt.) & -0.33 & 0.02 & $19.36^{* * *}$ & -0.26 & 0.02 & $14.63^{* * *}$ & -0.18 & 0.03 & $5.57^{* * *}$ \\
\hline & Angle & 0.59 & 0.03 & $17.25^{* * *}$ & 0.43 & 0.03 & $16.87^{* * *}$ & 0.33 & 0.08 & $4.35^{* * *}$ \\
\hline & Direction (Ant.-Alt.) $\mathrm{x}$ angle & 0.48 & 0.05 & $10.51^{* * *}$ & 0.38 & 0.05 & $7.99^{* * *}$ & 0.26 & 0.07 & $4.01^{* * *}$ \\
\hline & Direction (Cl.-Alt.) x angle & -0.41 & 0.04 & $9.30^{* * *}$ & -0.34 & 0.04 & $7.79^{* * *}$ & -0.21 & 0.06 & $3.21^{* *}$ \\
\hline \multirow[t]{4}{*}{ Model 3} & Intercept & 8.44 & 0.05 & 169.89 & 2.94 & 0.05 & 64.36 & -1.42 & 0.12 & 12.02 \\
\hline & Direction (Ant.-Cl.) & 0.04 & 0.02 & $2.38^{*}$ & 0.03 & 0.02 & 1.90 & -0.01 & 0.03 & 0.31 \\
\hline & Angle & 0.44 & 0.03 & $14.08^{* * *}$ & 0.31 & 0.03 & $11.65^{* * *}$ & 0.19 & 0.06 & $3.19^{* *}$ \\
\hline & Direction $\mathrm{x}$ angle & 0.07 & 0.03 & $2.28^{*}$ & 0.04 & 0.03 & 1.31 & 0.05 & 0.07 & 0.74 \\
\hline
\end{tabular}

Note. Ant. = anticlockwise rotations; Cl. = clockwise rotations; Alt. $=$ alternating rotations. $* \mathrm{p}<0.05 ; * * \mathrm{p}<0.01 ; * * * \mathrm{p}<0.001$ 
Table 3. Local Target Word Measures.

\begin{tabular}{lllccc}
\hline & & & $\begin{array}{c}\text { First fixation } \\
\text { duration }\end{array}$ & $\begin{array}{c}\text { Gaze } \\
\text { duration }\end{array}$ & $\begin{array}{c}\text { Total fixation } \\
\text { time }\end{array}$ \\
\hline Upright & & High & $202(72)$ & $228(107)$ & $289(191)$ \\
& & Low & $226(72)$ & $254(96)$ & $353(262)$ \\
Anticlockwise & $30^{\circ}$ & High & $232(112)$ & $262(125)$ & $330(197)$ \\
& & Low & $246(83)$ & $301(144)$ & $390(245)$ \\
& $60^{\circ}$ & High & $277(93)$ & $409(289)$ & $521(512)$ \\
& & Low & $298(110)$ & $490(363)$ & $838(991)$ \\
Alternating & $30^{\circ}$ & High & $237(79)$ & $284(115)$ & $407(327)$ \\
& & Low & $265(79)$ & $384(261)$ & $542(419)$ \\
& $60^{\circ}$ & High & $324(142)$ & $800(689)$ & $1185(1032)$ \\
& & Low & $337(146)$ & $1143(998)$ & $2012(1673)$ \\
Clockwise & $30^{\circ}$ & High & $226(61)$ & $242(72)$ & $312(147)$ \\
& & Low & $260(86)$ & $297(117)$ & $413(253)$ \\
& $60^{\circ}$ & High & $296(102)$ & $468(240)$ & $613(449)$ \\
& & Low & $329(151)$ & $659(579)$ & $1029(1064)$ \\
& & & & &
\end{tabular}

Note. Mean (standard deviation) reading times on the target word in each sentence. All reading time measures are reported in $\mathrm{ms}$. 
Table 4. LME results for local measures.

\begin{tabular}{|c|c|c|c|c|c|c|c|c|c|c|}
\hline & & \multicolumn{3}{|c|}{ FFDur } & \multicolumn{3}{|c|}{ Gaze } & \multicolumn{3}{|c|}{ TotFixDur } \\
\hline & & $\mathrm{B}$ & $\mathrm{SE}$ & $\mathrm{t}$ & $\mathrm{B}$ & SE & $\mathrm{t}$ & $\mathrm{B}$ & SE & $\mathrm{t}$ \\
\hline \multirow[t]{7}{*}{ M1 } & Baseline (upright) & 5.32 & 0.03 & 198.45 & 5.41 & 0.04 & 145.21 & 5.60 & 0.06 & 91.05 \\
\hline & Alternating, $30^{\circ}$ & 0.16 & 0.03 & $5.35^{\text {*** }}$ & 0.28 & 0.05 & $6.06^{* * *}$ & 0.37 & 0.05 & $7.87^{* * * *}$ \\
\hline & Left, $30^{\circ}$ & 0.10 & 0.03 & $3.45^{* * *}$ & 0.15 & 0.04 & $3.36^{* * *}$ & 0.16 & 0.05 & $3.32^{* * *}$ \\
\hline & Right, $30^{\circ}$ & 0.13 & 0.03 & $4.48^{* * *}$ & 0.13 & 0.04 & $2.87^{* *}$ & 0.17 & 0.05 & $3.53^{* * *}$ \\
\hline & Alternating, $60^{\circ}$ & 0.40 & 0.04 & $9.91^{* * * *}$ & 1.17 & 0.08 & $14.00^{* * *}$ & 1.48 & 0.05 & $30.83^{* * *}$ \\
\hline & Left, $60^{\circ}$ & 0.29 & 0.03 & $8.33^{* * *}$ & 0.55 & 0.05 & $10.61^{* * *}$ & 0.65 & 0.05 & $13.82^{* * * *}$ \\
\hline & Right, $60^{\circ}$ & 0.36 & 0.04 & $8.82^{* * *}$ & 0.74 & 0.06 & $12.85^{* * *}$ & 0.84 & 0.05 & $17.81^{* * *}$ \\
\hline \multirow[t]{12}{*}{ M2 } & Intercept & 5.56 & 0.02 & 263.03 & 5.92 & 0.03 & 189.67 & 6.21 & 0.05 & 116.78 \\
\hline & Direction (Ant.-Alt.) & 0.09 & 0.02 & $4.52^{* * *}$ & 0.38 & 0.03 & $13.33^{* * *}$ & 0.52 & 0.03 & $16.77^{* * *}$ \\
\hline & Direction (Cl.-Alt.) & -0.04 & 0.02 & $2.08^{*}$ & -0.30 & 0.03 & $10.40^{* * *}$ & -0.42 & 0.03 & $13.64^{* * *}$ \\
\hline & Angle & 0.22 & 0.02 & $8.88^{* * *}$ & 0.64 & 0.03 & $18.48^{* * *}$ & 0.76 & 0.04 & $17.37^{* * *}$ \\
\hline & Freq & 0.08 & 0.02 & $5.20^{* * *}$ & 0.20 & 0.02 & $8.46^{* * *}$ & 0.32 & 0.03 & $12.61^{* * *}$ \\
\hline & Direction (Ant.-Alt.) x angle & 0.05 & 0.04 & 1.35 & 0.49 & 0.06 & $8.46^{* * *}$ & 0.61 & 0.06 & $9.82^{* * *}$ \\
\hline & Direction (Cl.-Alt.) x angle & -0.01 & 0.04 & 0.36 & -0.28 & 0.06 & $4.80^{* * * *}$ & -0.44 & 0.06 & $7.03^{* * * *}$ \\
\hline & Direction (Ant.-Alt.) x freq & 0.01 & 0.04 & 0.26 & 0.14 & 0.06 & $2.37^{*}$ & 0.12 & 0.06 & 1.94 \\
\hline & Direction (Cl.-Alt.) x freq & 0.03 & 0.04 & 0.73 & -0.07 & 0.06 & 1.18 & -0.07 & 0.06 & 1.10 \\
\hline & Angle $\mathrm{x}$ freq & -0.05 & 0.03 & 1.39 & 0.04 & 0.05 & 0.82 & 0.20 & 0.05 & $3.97^{* * *}$ \\
\hline & Direction (Ant.-Alt.) $\mathrm{x}$ angle $\mathrm{x}$ freq & -0.09 & 0.08 & 1.08 & 0.04 & 0.11 & 0.33 & -0.01 & 0.12 & 0.05 \\
\hline & Direction (Cl.-Alt.) x angle $\mathrm{x}$ freq & 0.04 & 0.08 & 0.46 & -0.04 & 0.11 & 0.33 & -0.08 & 0.12 & 0.62 \\
\hline \multirow[t]{8}{*}{ M3 } & Intercept & 5.53 & 0.02 & 274.13 & 5.80 & 0.03 & 200.36 & 6.05 & 0.05 & 110.91 \\
\hline & Direction (Ant.-Cl.) & 0.05 & 0.02 & $2.57^{*}$ & 0.09 & 0.03 & $3.42^{* * *}$ & 0.10 & 0.03 & $3.41^{* * *}$ \\
\hline & Angle & 0.20 & 0.03 & $7.00^{* * *}$ & 0.51 & 0.04 & $14.06^{* * *}$ & 0.59 & 0.05 & $11.85^{* * *}$ \\
\hline & Frequency & 0.09 & 0.02 & $4.43^{* * *}$ & 0.16 & 0.03 & $6.55^{* * *}$ & 0.29 & 0.03 & $10.08^{* * *}$ \\
\hline & Direction $\mathrm{x}$ angle & 0.04 & 0.04 & 1.02 & 0.21 & 0.05 & $4.20^{* * * *}$ & 0.17 & 0.06 & $3.02^{* *}$ \\
\hline & Direction $\mathrm{x}$ freq & 0.04 & 0.04 & 1.00 & 0.07 & 0.05 & 1.33 & 0.05 & 0.06 & 0.95 \\
\hline & Angle $\mathrm{x}$ freq & -0.02 & 0.04 & 0.63 & 0.03 & 0.05 & 0.54 & 0.19 & 0.06 & $3.33^{* * *}$ \\
\hline & Direction $\mathrm{x}$ angle $\mathrm{x}$ freq & -0.05 & 0.08 & 0.62 & 0.00 & 0.10 & 0.01 & -0.08 & 0.11 & 0.67 \\
\hline
\end{tabular}

Note. $\mathrm{M} 1=$ Model 1; M2 = Model 2; M3 = Model 3. FFDur $=$ first fixation duration; Gaze = gaze duration; TotFixDur $=$ total fixation duration. Ant. $=$ anticlockwise rotations; $\mathrm{Cl} .=$ clockwise rotations; Alt. = alternating rotations. ${ }^{*} \mathrm{p}<0.05 ; * * \mathrm{p}<0.01 ; * * * \mathrm{p}<0.001$ 


\begin{tabular}{|c|c|c|}
\hline \multicolumn{3}{|c|}{ Normal upright text } \\
\hline 30 & degrees & lefx \\
\hline 30 & degrees & ママ9々大 \\
\hline 30 & degnees & $2<x e x h$ \\
\hline o & 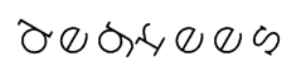 & $y \theta x, x$ \\
\hline 50 & grakcos & 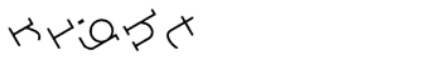 \\
\hline$c$ & gea yo ers & orxespo \\
\hline
\end{tabular}

Figure 1. Example stimuli in each of the text presentation conditions. In addition to a control condition of normal upright text, six combinations of magnitude $\left(30^{\circ}\right.$ or $\left.60^{\circ}\right)$ and direction (clockwise, anticlockwise or alternating clockwise/anticlockwise) of individual letter rotations were presented. 
Reading rotated letter sentences

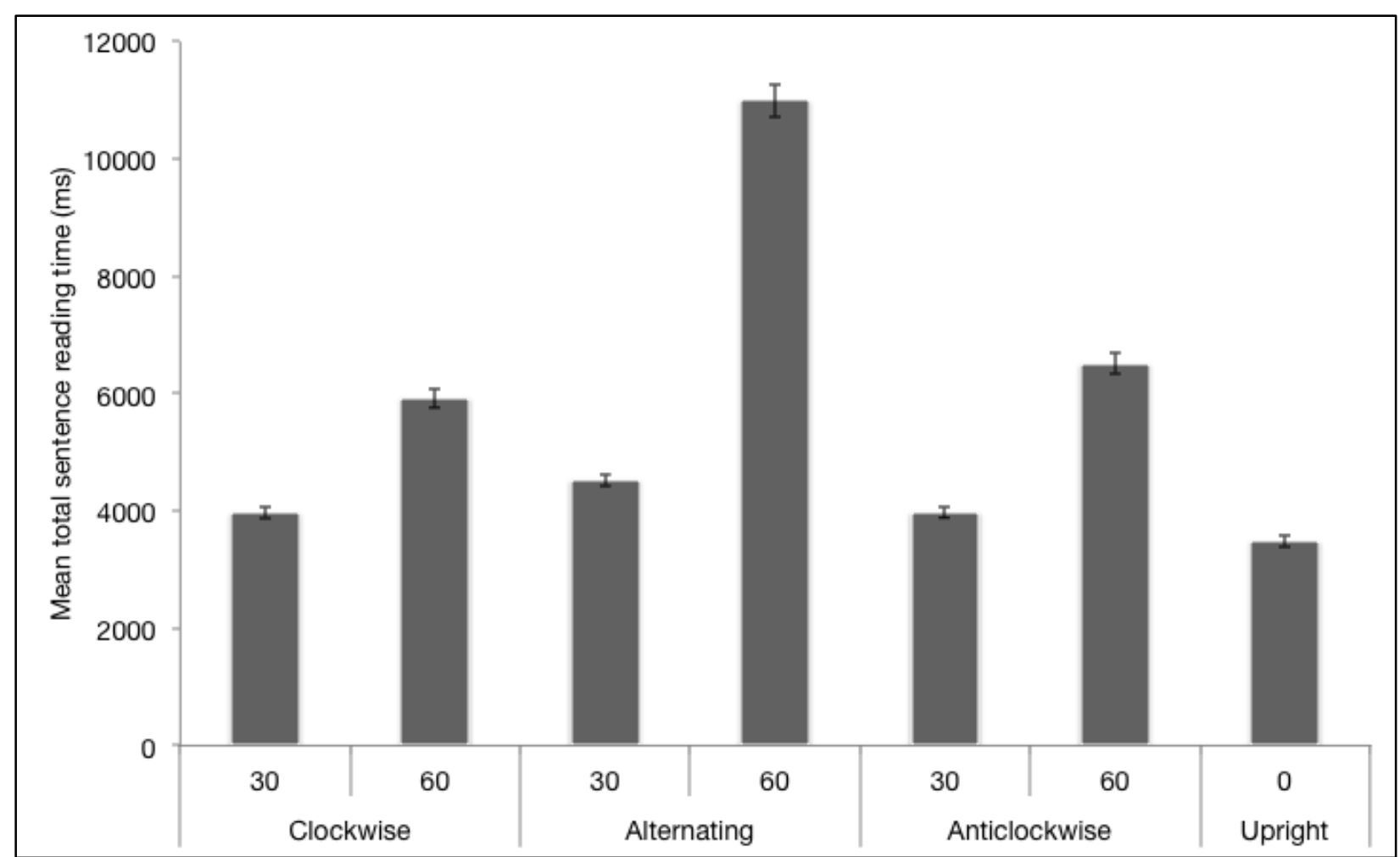

Figure 2. Total sentence reading times in each of the text presentation conditions. Error bars show the standard error in each condition. 


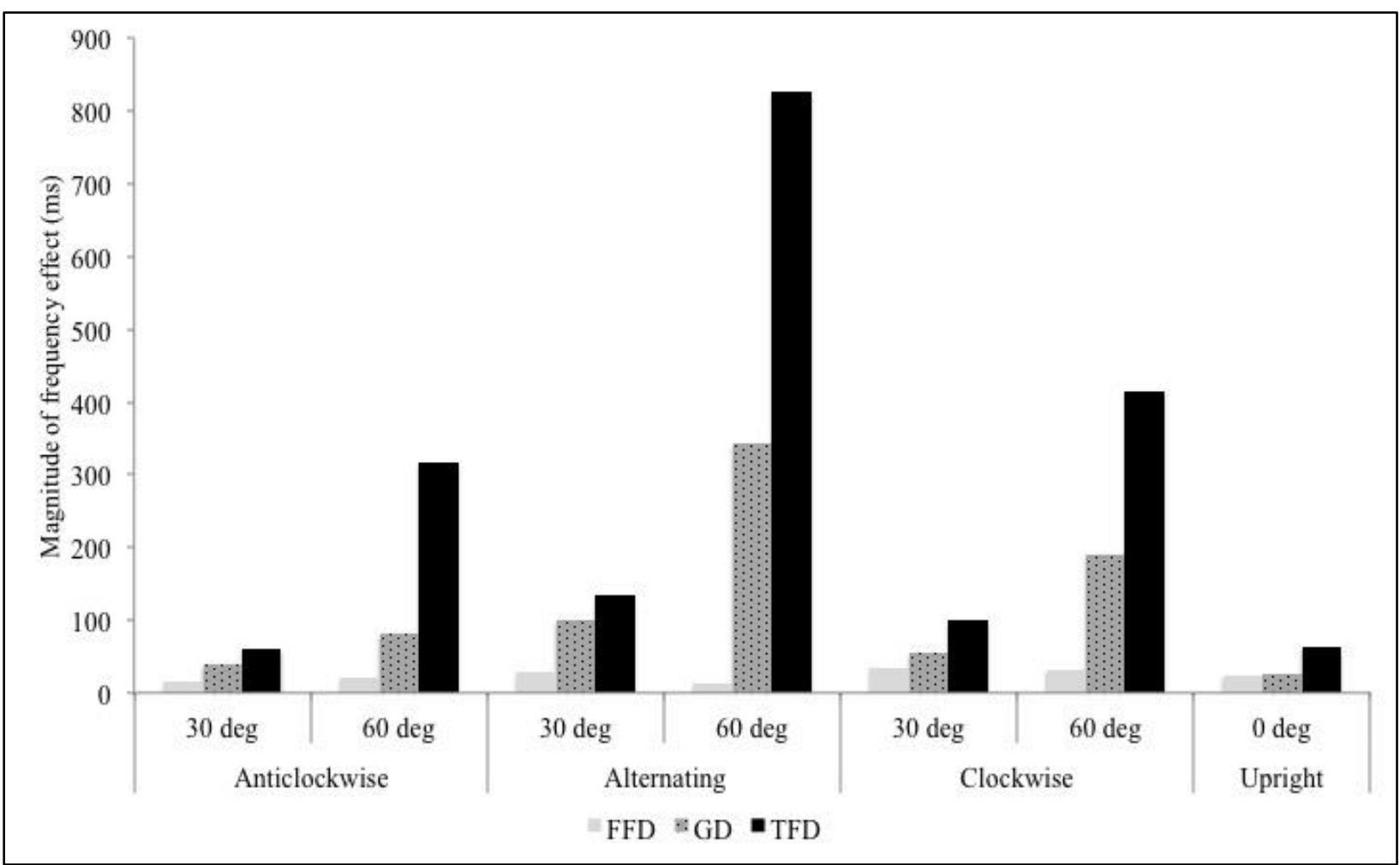

Figure 3. The magnitude of the word frequency effect in milliseconds (Low frequency - High Frequency) for each rotation condition for the four dependent measures examined on the target word. FFD $=$ First Fixation Duration, GD= Gaze Duration, TFD= Total Fixation Duration. 